\title{
Hyperprogression to a dual immune blockade followed by subsequent response with cabozantinib in metastatic poor-risk clear cell renal cell carcinoma with NOTCH mutation This article has an addendum: Oncotarget. 2022; 13:1245-1245.
} \author{
Javier Molina-Cerrillo ${ }^{1}$, Teresa Alonso-Gordoa ${ }^{1}$, Alfredo Carrato ${ }^{1}$ and Enrique Grande ${ }^{2}$ \\ ${ }^{1}$ Medical Oncology Department, Ramón y Cajal University Hospital, Madrid, Spain \\ ${ }^{2}$ MD Anderson Cancer Center, Madrid, Spain \\ Correspondence to: Javier Molina-Cerrillo, email: javier.molinace@gmail.com \\ Keywords: immunotherapy; renal cell carninoma; cabozantinib; NOTCH \\ Received: February 14, $2020 \quad$ Accepted: April 27, $2020 \quad$ Published: June 02, 2020 \\ Copyright: Molina-Cerrillo et al. This is an open-access article distributed under the terms of the Creative Commons Attribution \\ License 3.0 (CC BY 3.0), which permits unrestricted use, distribution, and reproduction in any medium, provided the original author \\ and source are credited.
}

\section{ABSTRACT}

\begin{abstract}
Currently, more and more patients receive first-line treatment with immunotherapy combinations and not all patients respond in metastatic renal cell carcinoma. After IO-IO progression, we don't have a standard of treatment because it is not available prospective data on this setting. We present the case of a patient with metastatic renal cell carcinoma who suffered hyperprogression with IO-IO combination in first line. Second line with cabozantinib results in a deep response of the disease. We performed a Foundation One testing to the patient which showed a mutation in NOTCH. The molecular mechanism to explain patient's response, it's the probably crosstalk between MET and NOTCH pathway. Nowadays, there is not clear the subsequent treatment in those patients who progress to IO-IO first line. More efforts in biomarkers development should be made to better selection of patients treatment along the disease.
\end{abstract}

\section{INTRODUCTION}

We present the case of a 50-year-old male who came to the emergency room in March 2019 due to the recent appearance of a mass in the lower region of the left thigh.

Magnetic resonance was performed and described a $4.5 \times 4 \mathrm{~cm}$ lesion in the thickness of the vast intermediate muscle that was suspicious of a primary tumor of the soft tissue vs metastases from another origin. Body CT scan revealed the presence of myocardial implants with extension towards the left ventricular lumen measuring up to $50 \mathrm{~mm}$ and pericardial implants, micronodules in both lungs, several lesions in the right gluteus, up to $21 \mathrm{~mm}$ and a mass in the upper pole of the left kidney of $6.8 \times 5.5 \mathrm{~cm}$.

The case was discussed at the genitourinary tumor board and decided to perform a biopsy of both the mass in the thickness of the intermediate layer and the kidney. The pathological results showed that both lesions were affected by a clear cell carcinoma (ccRCC), Fuhrman grade IV.

On physical examination, the patient presented a mass in the left thigh region and Karnofsky Index (KI) was $90 \%$. The blood test showed: Hemoglobin $11.7 \mathrm{gr} / \mathrm{dl}$ (Reference[Ref]: 13-17.5 gr/dL), Neutrophils 9,450/ $\mu \mathrm{L}$

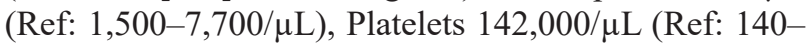
$400,000 / \mu \mathrm{L}$ ), LDH $412 \mathrm{U} / \mathrm{L}$ (Ref: 140-240 U/L), Calcium $9.2 \mathrm{mg} / \mathrm{dL}$ (Ref: $8.7-10.3 \mathrm{mg} / \mathrm{dL}$ )

Considering the final diagnosis as a poor prognosis clear cell renal cell carcinoma stage IV based on the MSKCC and IMDC prognostic criteria, the patient was offered to receive first-line treatment with Nivolumab $3 \mathrm{mg} / \mathrm{Kg}$ and Ipilimumab $1 \mathrm{mg} / \mathrm{Kg}$ every 3 weeks in the induction phase in April 2019 based on Checkmate 214 results [1].

After 2 cycles, in May 2019, the patient came to the clinic showing a significant clinical deterioration with a KI of $50 \%$. In the physical examination, the patient presented new painful and palpable masses in the left dorsolumbar region and right gluteus. The radiological assessment confirmed the clinical suspicious of disease progression with an increase in the renal tumor mass of $7.7 \times 5.9 \mathrm{~cm}$, new intraabdominal implants in the right perirenal space of $4 \mathrm{~cm}$ and left of $3 \mathrm{~cm}$, right hypochondrium of $5.5 \mathrm{~cm}$ and 
left iliac fossa of $4 \mathrm{~cm}$. New implants were also identified within the soft tissue at different levels: retropectoral, axillary, paravertebral, gluteus and psoas with a diameter between $3.8 \mathrm{~cm}$ to $4.5 \mathrm{~cm}$. In addition, bilateral lung nodules of new appearance were reported, being the largest ones of $6.5 \mathrm{~mm}$ in left superior lobe, as well as disease progression at myocardial and pericardial sites.

According to this situation of hyperprogression, we considered performing a foundation one in primary tumor sample achieving mutations in VHL (L158fs*14), NOTCH2(R65*), BAP1(P488fs*82). MSI-stable, low mutational tumor burden. Considering the mutation in $\mathrm{NOTCH}$ and its possible relationship with $\mathrm{HGF} / \mathrm{MET}$ pathway [2, 3] (Figure 1) and knowing that the alterations in BAP1 are related with worse prognosis, we decided to offer the patient a second-line treatment with cabozantinib $60 \mathrm{mg}$ daily. The patient began this treatment in early June 2019 with close monitoring of adverse events and tumor assessment. After 2 weeks of treatment, the patient began to experience significant clinical improvement, recovering to a $\mathrm{KI}$ of $90 \%$ and with an objective tumor reduction of the visible implants in the left dorsolumbar region, right gluteus muscle and disappearance in vast intermediate lesion. Treatment with cabozantinib was well tolerated with grade II diarrhea that had an adequate response to loperamide treatment.

The radiological assessment performed in July 2019 showed that most of the soft tissue implants had disappeared and only some of them continued with a significant reduction in size, as well as those in the peritoneum, myocardial, pericardial tissue and lung.

The patient is currently under treatment with cabozantinib at the same dose level and acceptable tolerability. The last radiological evaluation performed in November 2019 showed the disappearance of the soft tissue lesions, practical resolution of peritoneal implants, no visible lung disease and significant reduction in size of the primary renal tumor mass (Figure 2).

In the last years, phase III clinical trials are including new practice-changing combinations in the first line treatment of advanced kidney cancer, based in double IO (IO-IO) or in combination with antiangiogenics (IO-VEGFR). These combinations are interestingly increasing the complete response rates and survival [4]. However, patients may develop eventual resistance to these combinations or being primary refractory. In pivotal

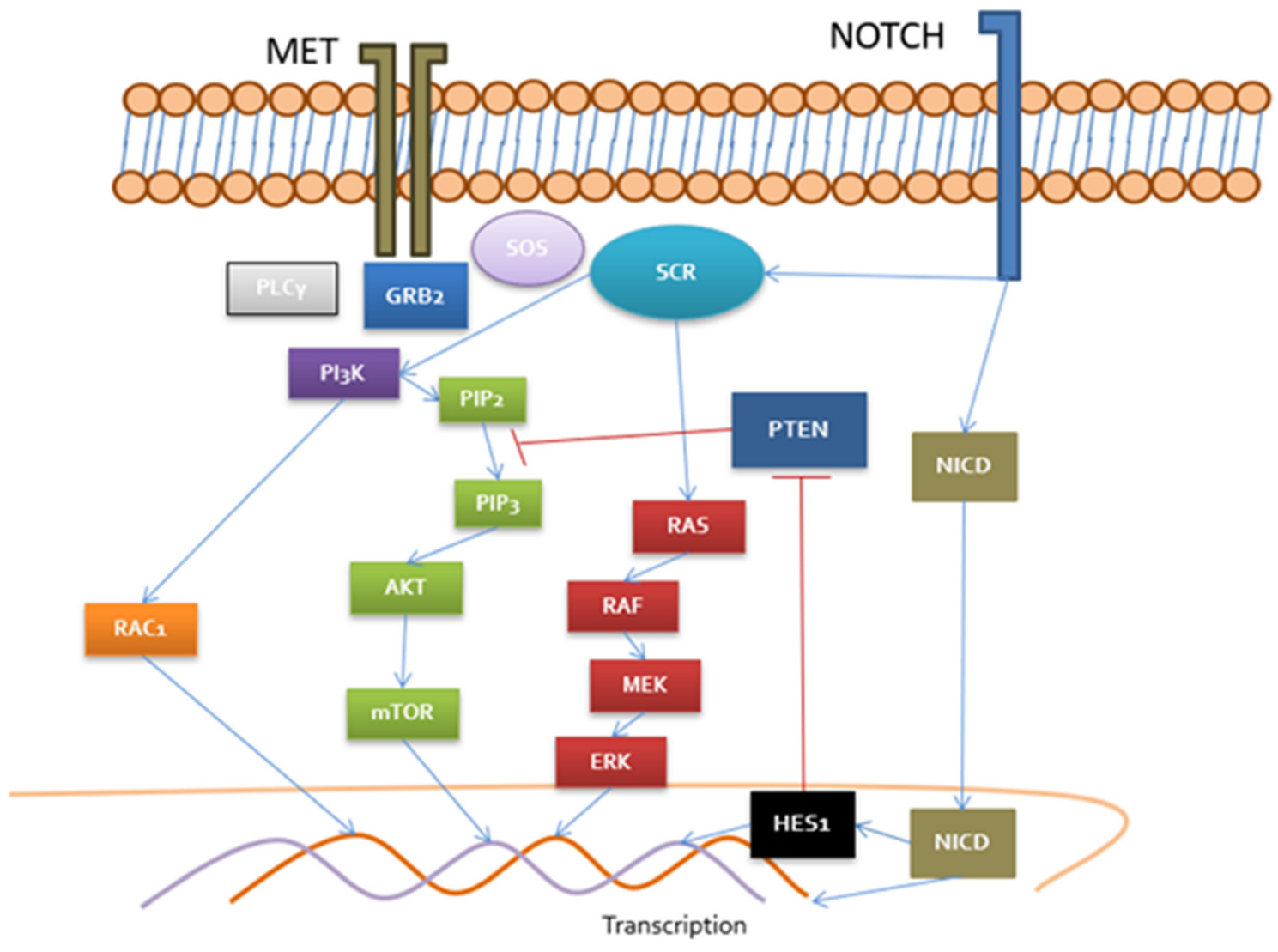

Figure 1: Cross-talk between MET/NOTCH pathways MET recruit PLC $\gamma$, GRB2 and SOS which activate DAG receptors (PKC), RAS/RAF/MEK, PI3K/RAC and Akt/mTOR. PI3K pathway are negatively regulated by PTEN. NOTCH upregulate HES1 transcriptional factor implied in negative control of PTEN. Moreover, SCR in a central pathway in MET and NOTCH activation consisting in a key regulator in both signalization routes. NOTCH is capable to control MET promoter and MET regulate expression of delta promoter (NOTCH ligand) in nucleus. 
trials, as much as $11 \%$ of the patients treated with the combination of IO-VEGFR and 20\% when used the dual blockade of IO-IO combinations are showing radiology progression as best response according to RECIST criteria. No prospective data are reported so far after failure to combinations as a first approach in metastatic RCC patients, therefore VEGFR inhibitors are widely used and recommended in main guidelines based on retrospective series.

Given the unequivocal clinical and radiology hyperprogression that this patient presented, a second line treatment that could induce an early response was required. In this setting, we considered that cabozantinib might be the best available option based on its mechanism of action as an inhibitor of VEGFR, mainly type 2, but also of other therapeutic targets involved in molecular mechanisms of tumor progression and resistance, such as Axl and c-MET, taking into account the alteration in NOTCH2 of the patient and its relationship with this molecular pathways and MET promoter [2, 3, 5] and its favorable results in disease control rate obtained in different clinical trials [6].
As far as we know, there are no reported cases of hyperprogression in kidney cancer patients receiving the combination of nivolumab and ipilimumab. In addition, there are few data coming from retrospective series on the use of TKI after progression to previous IO treatment in metastatic renal cancer. Those data show some activity from TKIs in this setting, but in patients not responding to the IO-IO combination, response durations are below 5 months, representing a subgroup of patients with a particularly poor prognosis. This evidence is even more limited in the case of cabozantinib, as only a small percentage of patients included in these retrospective studies received this drug $[7,8]$. In this report, the patient is benefiting from an early and profound response of cabozantinib for at least 6 months with an improvement in his quality of life.

In conclusion, there may be hyperprogressions with the new combinations in RCC, the NOTCH pathway may be activated in some patients and MET inhibition may be key to its control. In this case it is demonstrated that a TKI such cabozantinib can control hyperprogression phenomena in $2 \mathrm{~L}$ of $\mathrm{m}$ ccRCC. Clinical trials are currently

\begin{tabular}{|c|c|c|c|c|c|}
\hline ECOG $1 / \mathrm{KI} 90 \%$ & ECOG 3/KI 50\% & $\mathrm{ECOG} 2 / \mathrm{KI} 70 \%$ & & ECOG 1/KI 90\% & $\Rightarrow$ \\
\hline \multicolumn{2}{|c|}{ Nivolumab/lpilimumab } & \multicolumn{3}{|c|}{ Cabozantinib } & $\rightarrow$ \\
\hline 19/MAR/2019 & $30 / \mathrm{MAY} / 2$ & & 29/JULY/2019 & $02 / N O V / 2019$ & \\
\hline
\end{tabular}

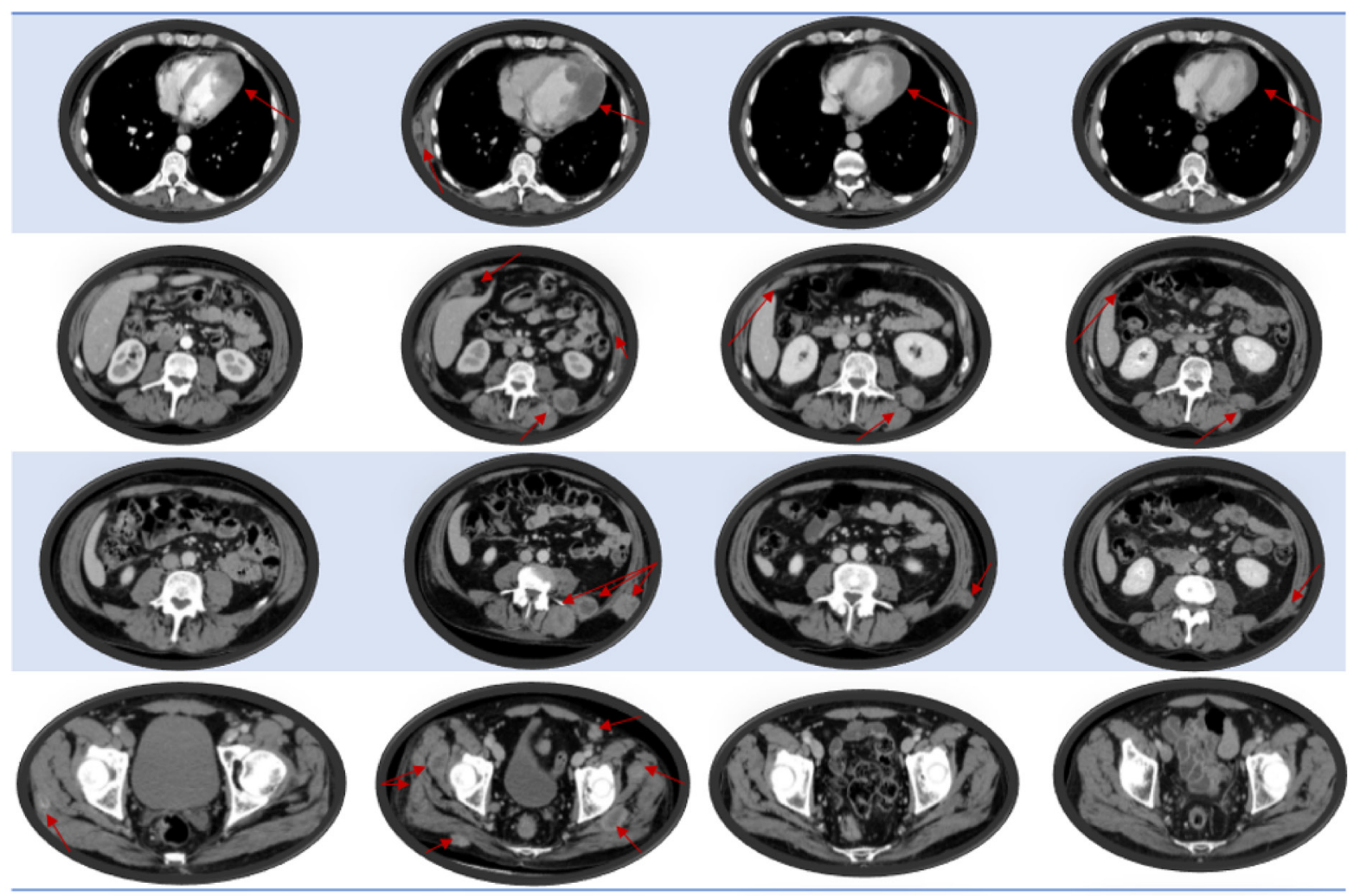

Figure 2: Patient's radiology and clinical outcome according to systemic treatments. 
ongoing in this setting trying to elucidate, prospectively, which is the best strategy [8-10]. In this sense, biomarker research is essential to identify those tumor profiles that provide information about the best approach in the first line setting and beyond.

\section{CONFLICTS OF INTEREST}

Javier Molina-Cerrillo: Declares no conflict of interest. Teresa Alonso-Gordoa: Pfizer, Ipsen, BristolMyers Squibb, Roche, Eusa Pharma, MerckSharp\&Dohme (C/A, SAB), Roche (RF). Alfredo Carrato: Declares no conflict of interest. Enrique Grande: Pfizer, BristolMyers Squibb, Ipsen, Roche, Eisai, Eusa Pharma, MerckSharp\&Dohme, Sanofi-Genzyme, Adacap, Novartis, PierreFabre, Lexicon, Celgene (C/A, SAB), Pfizer, AstraZeneca, MTEM/Threshold, Roche, Ipsen, Lexicon (RF).

\section{REFERENCES}

1. Motzer RJ, Tannir NM, McDermott DF, Arén Frontera O, Melichar B, Choueiri TK, Plimack ER, Barthélémy P, Porta C, George S, Powles T, Donskov F, Neiman V, et al. Nivolumab plus Ipilimumab versus Sunitinib in Advanced Renal-Cell Carcinoma. N Engl J Med. 2018; 378:12771290. https://doi.org/10.1056/NEJMoa1712126. [PubMed]

2. Gutierrez A, Look T. NOTCH and PI3K-AKT Pathways Intertwined. Cancer Cell. 2007; 12:411-413. https://doi. org/10.1016/j.ccr.2007.10.027. [PubMed]

3. Abounader RT. Regulation of c-Met-dependent gene expression by PTEN. Oncogene. 2004; 23:9173-9182. https://doi.org/10.1038/sj.onc.1208146. [PubMed]

4. Motzer RJ, Rini BI, McDermott DF, Arén Frontera O, Hammers HJ, Carducci MA, Salman P, Escudier B, Beuselinck B, Amin A, Porta C, George S, Neiman V, et al. Nivolumab plus ipilimumab versus sunitinib in firstline treatment for advanced renal cell carcinoma: extended follow-up of efficacy and safety results from a randomised, controlled, phase 3 trial. Lancet Oncol. 2019; 20:1370-1385. https://doi.org/10.1016/S1470-2045(19)30413-9. [PubMed]
5. Alonso-Gordoa T, García-Bermejo ML, Grande E, Garrido P, Carrato A, Molina-Cerrillo J. Targeting Tyrosine kinases in Renal Cell Carcinoma: "New Bullets against Old Guys. Int J Mol Sci. 2019; 20:1901. https://doi.org/10.3390/ ijms20081901. [PubMed]

6. Choueiri TK, Escudier B, Powles T, Mainwaring PN, Rini BI, Donskov F, Hammers H, Hutson TE, Lee JL, Peltola K, Roth BJ, Bjarnason GA, Géczi L, et al. Cabozantinib versus Everolimus in Advanced Renal-Cell Carcinoma. N Engl J Med. 2015; 373:1814-1823. https:// doi.org/10.1056/NEJMoa1510016. [PubMed]

7. Auvray M, Auclin E, Barthelemy P, Bono P, KellokumpuLehtinen P, Gross-Goupil M, De Velasco G, Powles T, Mouillet G, Vano YA, Gravis G, Mourey L, Priou F, et al. Second-line targeted therapies after nivolumabipilimumab failure in metastatic renal cell carcinoma. Eur J Cancer. 2019; 108:33-40. https://doi.org/10.1016/j. ejca.2018.11.031. [PubMed]

8. Bellmunt J, Esteban E, Muro XGD, Sepúlveda JM, Maroto P, Gallardo E, Alba AGD, Etxaniz O, Guix M, Larriba JLG, Arranz JA, Redrado M, Calvo A, et al. Pazopanib as Second-line Antiangiogenic Treatment in Metastatic Renal Cell Carcinoma After Tyrosine Kinase Inhibitor (TKI) Failure: A Phase 2 Trial Exploring Immune-related Biomarkers for Testin $\mathrm{g}$ in the Post-immunotherapy/ TKI Era. Eur Urol Oncol. 2019 Aug 30. https://doi. org/10.1016/j.euo.2019.07.014. [Epub ahead of print]. [PubMed]

9. Lee C, Shah A, Makker V, et al. Phase 2 Study of Lenvatinib plus Pembrolizumab for Disease Progression after PD-1/ PD-L1 Immune Checkpoint Inhibitor (ICI) in Metastatic Clear Cell (mcc) Renal Cell Carcinoma (RCC): Results of an interim analysis. 18th International Kidney Cancer Symposium, Miami. 2019 Nov 15-16.

10. Rini BI, Huseni M, Atkins MB, McDermott DF, Powles TB, Escudier B, Banchereau R, Liu L, Leng N, Fan J, Doss J, Nalle S, Carroll S, et al. Molecular correlates differentiate response to atezolizumab (atezo) + bevacizumab (bev) vs sunitinib (sun): results from a Phase III study (IMmotion151). Proffered paper session. ESMO 2018 Congress, Barcelona. 2018 Oct 20. 